\title{
A Guide to Publication in Educational Technology
}

\author{
Steve Chi-Yin Yuen \\ The University of Southern Mississippi \\ Patrivan K. Yuen \\ William Carey University \\ Xiaojing Duan \\ University of Notre Dame
}

\begin{abstract}
This guide provides journal information to over 40 journals that are appropriate for the publication of articles in educational technology. Also, it discusses the process of planning and writing a journal article, submitting to journals, the peer reviewing process, and steps toward publishing in academic journals within the field of educational technology. Furthermore, the guide provides tips to getting published and offers helpful suggestions.
\end{abstract}

Keywords: guide, journal, publish, publication, educational, technology, instructional

\section{Introduction}

Scholarly productivity is one of the most important and controversial requirements for success in higher education. The competition for tenure-track faculty positions in academia puts increasing pressure on professors and researchers to publish scholarly work frequently (Maddux \& Liu, 2005). All professors in higher education must publish to survive. Successful publications in refereed, academic journals improves a professor's visibility and his/her institution's academic reputation that may help secure future research funding. Professors who focus on non-publishing related activities such as teaching and service, or who publish infrequently, or whose publications are not published in refereed or reputable academic journals, may find themselves out of contention for available tenure-track positions.
Writing a journal article can be an overwhelming process. This guide is prepared to assist university faculty members, as well as graduate students, in preparing and submitting manuscripts for publication in academic journals. The intent is to facilitate publication, research, and other scholarly activities in the field of educational technology.

\section{Establishing a Writing Plan}

Successful publishing begins with good planning. You should consider first the purposes for publishing, the scope of your article, and the audience from whom you are writing (Klingner, Scanlon, \& Pressley, 2005). Also, it is important to identify the idea and/ or the target journal. Most authors prefer to 
have the idea first and then look for a journal to publish the article. Some prefer to identify a journal and then come up the idea for a topic appropriate for the journal and its audience. Nonetheless, a journal should be targeted after a topic is decided.

For the purpose of tenure and promotion, publications in some journals count much more than others. Peer-reviewed journals are more prestigious than non peer-reviewed journals. Journals in the printed format are valued more than online journals, although online journals have become more acceptable in the field of educational technology. Publications in the first-tiered, peer-reviewed journals are viewed more favorably. Klinger, Scanlon, and Pressley (2005) point out a number of factors that serve to indicate a well-regarded journal:

- Wide circulation indicates more readers.

- A low acceptance rate indicates that the journal select only the best articles to publish.

- Well-known editor(s) and editorial board members indicate the reputation of the journal.

- The journal is cited often.

- A high journal impact factor indicates that the "average article" in the journal is cited frequently in a given period.

- High visibility indicates that the journal is indexed in multiple computerized databases.

To determine which journals would be a good fit for your manuscript, you should take time to research the potential journals and look for journals that publish similar types of work targeted for the same audiences to reach. You can go to the library or go online to browse through the potential journals. Furthermore, obtaining current information about the journals targeted for your article is helpful. Information such as frequency of issue, publication format, circulation, audience, acceptance rate, refereed/non refereed, number of readings, desired length of articles, preferred style, submission and review process, and publishing fee are important and can help you determine the target journal. Neglecting to research the appropriateness of a journal before submitting a manuscript is a common error (Klingner, Scanlon, \& Pressley, 2005).

Traditionally, most authors seek journal information by e-mailing the editor or searching on the Web. However, this requires a lot of time and effort to locate the journal information. In order to provide prospective authors with an easy access to the information about the educational technology journals, an online Educational Technology Journal Survey was conducted in April 2007 to collect journal information from the editors of various journals related to educational technology. The intent of the survey was to create an educational technology journal database that provided the important journal information needed by the prospective authors. The survey consisted of 27 items and provided useful publication information that included journal title, name of editor, email address, frequency of issue, publication format, circulation, audience, acceptance rate, refereed/non refereed journal, number of readings, desired length of articles, preferred style, submission and review process, and publishing fee if any. The online Educational Technology Journal Survey is shown in Figure 1 on the next page.

Seventy editors from various journals worldwide were identified and invited to participate in the survey. After 6 weeks and several follow-ups, 42 editors completed the survey online with a usable return rate of 60 percent. The results indicate that most of educational technology journals publish 4 issues per year. Sixty-three percent of the educational technology journals are published in printed format. The acceptance rate varies and ranges from $9 \%$ to $80 \%$. The average 


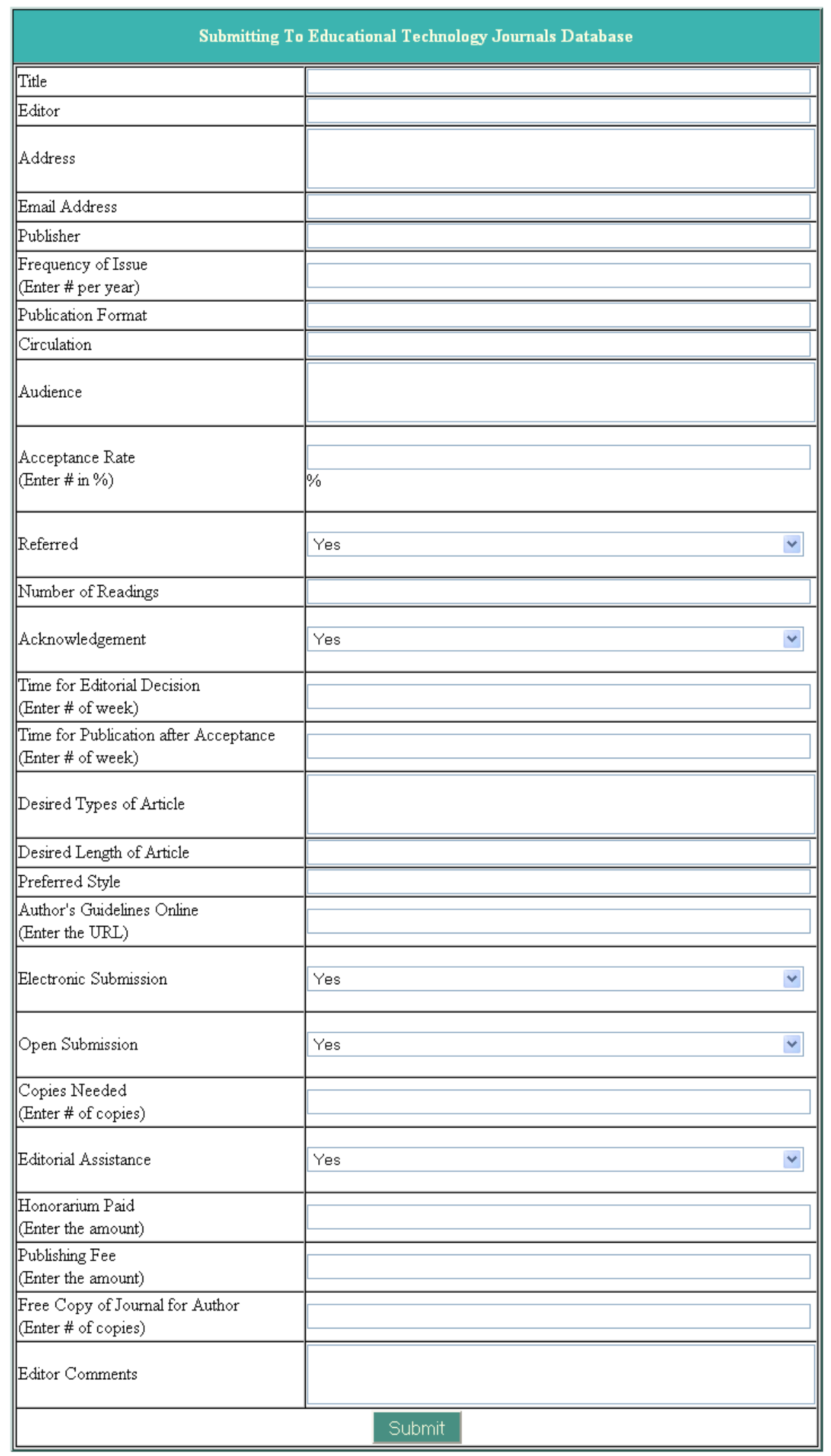

Figure 1. Submitting information to journal database 
acceptance rate is about $32 \%$. Ninety-three percent of the journals surveyed are refereed and only $7 \%$ are non-refereed. The number of readings required by the editorial review board ranges from 1 to 8 times with an average of 2.7 times. On the average, author takes about 12 weeks for receiving editorial decision and another 20 weeks for getting an article to publish. All educational technology journals participated in the survey have open submission policy and $95 \%$ of these journals have author's guidelines available online. Most educational technology journals prefer APA style (74\%) and allow an electronic submission (95\%). Seventy-nine percent of these journals provide editorial assistance to help authors revise their manuscripts. Ninety-five percent pay no honorarium to authors. However, $69 \%$ of the journals provide complimentary issues to authors.

There are several types of educational technology journals that publish varying types of articles for a variety of audiences. You should determine the audience, types of articles published in the journal, types of journal, acceptance rate, time for editorial decision, and desired length of article prior to preparing and submitting a manuscript. This can be accomplished by reviewing recent issues of the journal. A review of recent issues also helps determine if the journal has recently published articles on a similar topic or with similar content. However, the Educational Technology Journal Survey provides these helpful information with ease to those who want to publish their papers in the field of educational technology, especially to graduate students and junior faculty who are pursuing tenure and promotion. The complete information on all participated editors and their journals is available online at $A$ Guide to Publication in Educational Technology Web site [journal.yuen.us]. You can use the basic and advanced search tools provided on this
Web site to find the journal information before deciding on the target journal. For basic search tools, you can search the journal information by title, refereed journal, printed format, online format, or electronic submission [see Figure 2 on the next page]. Also, an advanced search tool is provided to filter the journals based on the following criteria selected: (a) preferred publication format (printed or online format), (b) refereed or non-refereed, (c) ranges of acceptance rate, and (d) submission format (electronic or snail mail) [see Figure 3 on the next page]. Once a journal is chosen from the list provided by the search tool, the system will provide the complete journal information for the selected journal [see Figure 4 on the page after next]. A Guide to Publication in Educational Technology Web site will be updated from time to time and new journal information will be added. Currently, editors are welcome to submit their journal information for the inclusion in the journal database.

In general, there are different types of articles published in academic journals in educational technology: (a) research articles (both quantitative research and qualitative research), (b) descriptive articles, (c) practicebased articles, (d) position papers, and (e) book reviews. A major consideration that can help an author in selecting a journal is to determine the type(s) of articles that are commonly published. For instance, it is not productive to send position papers to researchbased journals. In addition, it is important for authors to determine the audiences, types of articles, and types of journal before actual writing. One of the most important things to do before settling on a specific journal is to look through several back issues. Not only do most journals print their author guidelines in each issue (and on a Website), but an examination of back issues will reveal valuable information about the average article length, statistical and 


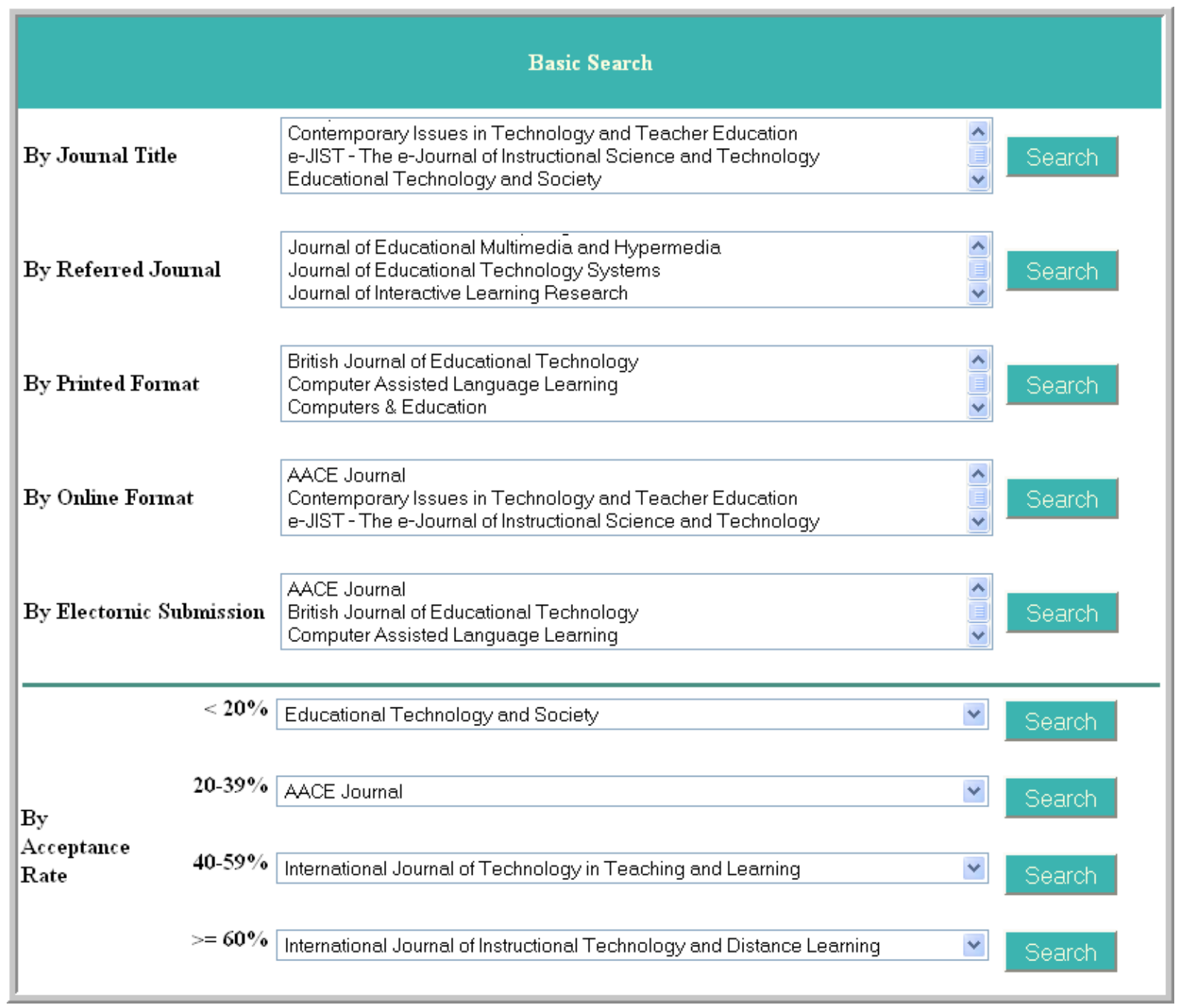

Figure 2. Basic journal search tools [http://journal.yuen.us]

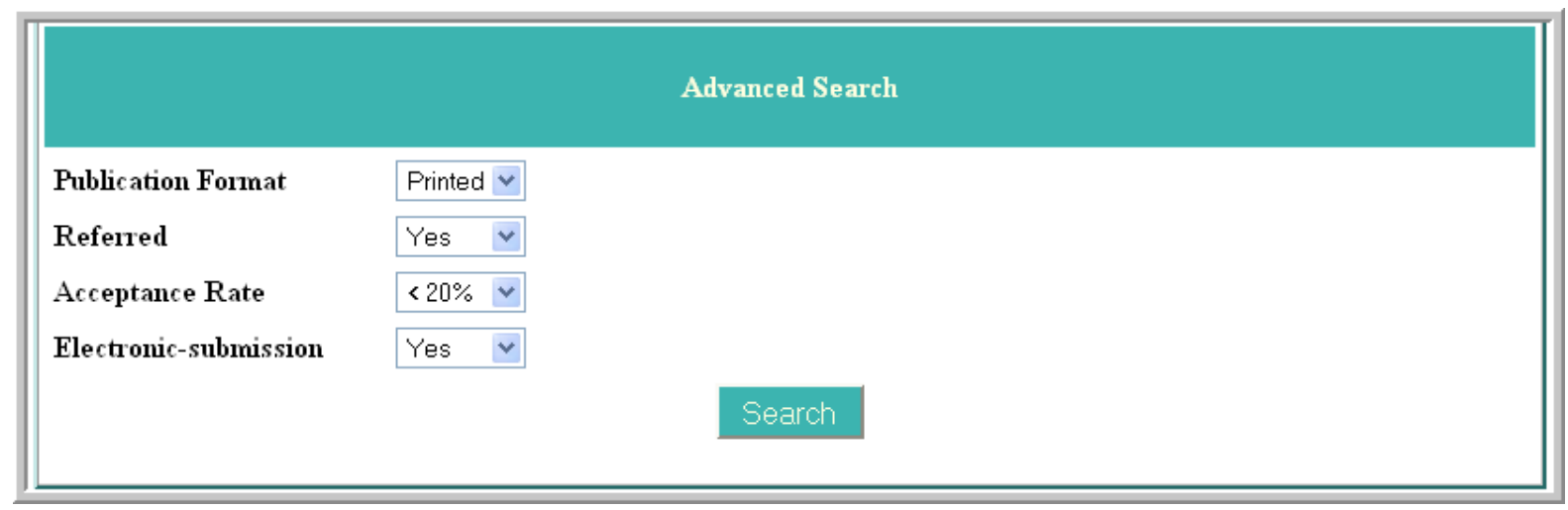

Figure 3. Advanced journal search tools [http://journal.yuen.us] 


\begin{tabular}{|c|c|}
\hline \multicolumn{2}{|r|}{ International Journal of Instructional Media } \\
\hline Title & International Journal of Instructional Media \\
\hline Editor & Dr. Phillip J. Sleeman \\
\hline Address & ITM, 149 Goose Lane, Tolland, CT 06084 \\
\hline Email Address & PLSleeman@aol.com \\
\hline Publisher & Westwood Press \\
\hline Freuquency of Issue & 4 per year \\
\hline Publication Format & Printed \\
\hline Circulation & 2000 \\
\hline Audience & International-govern., business, education \\
\hline Acceptance Rate (\%) & 35 \\
\hline Referred & Yes \\
\hline Number of Readings & 3 \\
\hline Acknowledgement & Yes \\
\hline Time for Editorial Decision & 36 Weeks \\
\hline $\begin{array}{l}\text { Time for Publication after } \\
\text { Acceptance }\end{array}$ & 2-3 Years \\
\hline Desired Types of Article & $\begin{array}{l}\text { Computer technology, computer mediated communications, instructional media and technology, } \\
\text { telecommunications, interactive video, videodisc, and software applications, instructional media } \\
\text { management, instructional development and systems, media research and evaluation }\end{array}$ \\
\hline Desired Length of Article & 15 pages including bibliography, references \\
\hline Preferred Style & $\mathrm{APA}, \mathrm{MLA}$ \\
\hline \begin{tabular}{|l|} 
Author's Guidelines Online \\
\end{tabular} & http://www. adprima com/jijm.htm \\
\hline Electronic Submission & No \\
\hline Open Submission & Yes \\
\hline Copies Needed & 3 \\
\hline Editorial Assistance & No \\
\hline Honorarium Paid & No \\
\hline Publishing Fee & No \\
\hline Free Copy of Jounal for Author & No \\
\hline Editor Comments & $\begin{array}{l}\text { For completed info on the Journal, please consult Web site at } \\
\text { http://www. adprima.com/ijim.htm. This is distributed to } 200+\text { countries throughout the world. }\end{array}$ \\
\hline
\end{tabular}

Figure 4. Sample journal search results

methodological complexity of typical articles, and a host of other relevant writing variables. There is really no good substitute for looking through a year or two of back issues for potential journals (Liu, Yuen, \& Maddux, 2007). Also, you may contact the editor to determine if a manuscript is appropriate for a specific journal. One common practice is to send a letter or email the editor for inquiry. A letter or email can produce various results. Some editors require such letters and will seldom publish unsolicited manuscripts. On the other hand, a positive response from an editor does not guarantee publication of the completed manuscript. Nonetheless, it is always a good idea to send an inquiry to the editor when in doubt.

\section{Writing the Article}

A good article begins with a good title. A good title should be clear, as short as possible, and most importantly, it should tell the reader exactly what the paper is about (Liu, Yuen, \& 
Maddux, 2007). When preparing a manuscript, you should identify the major issues or points, develop an outline, and write the article. It is a good idea to jot down ideas in free form and create a general outline. You can summarize the initial ideas into bullets. These bullets can later be organized into a logical structure and developed in the form of key sentences. A convincing outline can turn into a successful article (Socolofsky, 2004). Also, you should think about the questions before staring to write: What is the message of the article? What is the new result or contribution that you want to describe? What do you want to convince readers of? In the draft, tell readers what the article sets out to do, inform them what occurred, and discuss the findings (Socolofsky, 2004).

As you write the first draft, writing short abstracts of the articles can be used as referencing. This is much more manageable than having dozens of articles lying all over the place. After a draft has been completed, put the article away for a few days so that the content can be look at from a fresh perspective. You will notice things more often when reading through the draft a few days later. Revise the manuscript several times if needed. Also, pay close attention to your writing style. Here are some suggestions:

- Organize the paper logically and coherently.

- Have a clear structure.

- Establish the importance of the topic.

- Keep the writing clear, crisp, simple, informal, and direct.

- Use active verbs and straightforward language so readers can tell who did what, when, and where.

- Let the scholarship show in the depth and insight of what you have to say, not in the way said.

- Bear in mind that your task is to explain, describe and clarify, and not to impress the reader or to complicate the topic.

- Minimize your use of gimmicks such as capitalization, underlining, or italics.

- Use strong, simple openings and closings.

- Make sure no grammatical, spelling, or other mechanical errors are present.

- Follow the writing style designated by the chosen journal.

The length of the paper is critical for most journals. Some online journals are not strict about length, but most traditional print journals will specify a maximum length. This maximum length should never be exceeded, as overly lengthy papers are frequently rejected first hand. You should consult author guidelines for the journal before submission. Also, you can find the information on the desired length of article from A Guide to Publication in Educational Technology Web site. Although there is no general rule, most good manuscripts do not exceed 20-25 pages of double-spaced text, including title page, abstract, references, and all figures and tables (Liu, Yuen, \& Maddux, 2007).

\section{Submitting the Article}

It is important to aim for journals for which the manuscript is appropriate. Although you will get the best feedback from more prestigious journals, it is perfectly acceptable especially for new authors to consider submitting work to journals that are still of good quality, but not the most prestigious. The chances of getting published will be higher with these journals. This will build confidence and credibility. Therefore, try to match your manuscript with the most appropriate journal, given the substantive fit and personal circumstances (e.g., new author, applying for tenure and promotion). 
Before submitting your article to a journal, it is a good idea to ask your colleagues, coauthors, or someone in your field to critically analyze the manuscript. This evaluation can be extremely helpful in revising the article prior to submission. Also, you must follow editorial guidelines explicitly (i.e., correct number of copies, file format, correct style, etc). Doublecheck and triple-check your manuscript for grammatical errors and stylistic errors. You should not submit sloppy work. Also, many journals require masking the submission by removing all references to your name and other information that would reveal personal identity. When submitting a manuscript, it is common to enclose a cover letter to the editor that briefly describes the topic and why the manuscript would be of interest to the journal audience. Finally, send the manuscript out to only one journal at a time. It is unethical and not professional to submit the manuscript simultaneously to more than one journal. You may be surprised to be found out because many journals share editors or reviewers. You certainly do not want to spoil future chances of getting published by tarnishing your reputation.

\section{The Review Process}

After receiving a manuscript, most editors will acknowledge receipt of the manuscript and describe the review process. The amount of time before acknowledgement, number of readings, acceptance/rejection, and publication varies from journal to journal. Typically, the editor will conduct a preliminary editorial review and decide whether the manuscript is appropriate to his/her journal before sending out for review. If the editor determines that your manuscript is appropriate to send forward, he/she will generate a list of possible external reviewers who have expertise relevant to the focus of your manuscript and then select 2 to 3 from this list to review your manuscript. Many journals require "double-masked" review process in that the reviewers do not know the identity of the author of a manuscript and the author does not know the identity of the reviewers. They read the article and give their opinions and recommendations to the editor. The duration of the review process varies widely by journal (from several weeks to several months) depending on whether the journal uses an online submission system and how promptly the reviewers return their reviews back to the editor. It is a good idea to investigate the review timeline before submitting your manuscript (Klingner, Scanlon, \& Pressley, 2005). Again, this information can be found on $A$ Guide to Publication in Educational Technology Web site.

After receiving all reviews from the external reviewers, the editor will carefully read all reviewers' comments and the manuscript again before making a decision. Typically, the editor will send a letter or e-mail informing the decision, a summary of the reviewers' comments, and suggestions if any. The editorial decision may include one of the following: (a) accept the manuscript without changes; (b) accept it pending the completion of specific revisions; (c) encourage resubmission; or (d) reject.

It is extremely rare to have an article accepted as is. The most common decisions are "accept with revisions" and "reject." In the case of a re-submission subject to re-review, you should prepare a detailed response (pointby-point) to the reviewers' comments. For each major comment by a reviewer, summarize the comment in your response letter and then state how the comment has been addressed. The better the response, the easier it will be on the reviewers and the faster you are likely to get back the second round of decisions (Socolofsky, 2004). When resubmitting your manuscript, the editor will often send it back to the same reviewers for reviewing unless the old reviewers are no longer available. However, 
it is possible that some journals may have a policy of involving new reviewers (Klingner, Scanlon, \& Pressley, 2005).

Do not get too disappointed if your manuscript is rejected. Many published journal articles were rejected somewhere before they found a publication home. Also, you should learn from the process and try to improve your manuscript. You should take time to read and understand the comments and suggestions from the editor as well as the reviewers. This could be very helpful for revising or rewriting your manuscript for submitting to other journals.

\section{Tips for Successful Publishing}

Previous research and opinion papers have identified some common problems in preparing manuscripts that report on research findings. These problems frequently contribute to rejection. They are (a) lack of fit between the manuscript and the chosen journal (poor topic selection), (b) failure to establish the importance of the topic, (c) grammatical, spelling, or other mechanical errors, (d) failure to employ the writing style (such as APA) designated by the chosen journal, (e) poor choice of title, (f) lack of organization, (g) methodological problems, (h) data analysis problems, (i) lack of coherent conclusions, limitations, or implications, and (j) incomplete or otherwise inappropriate literature review (Liu, Yuen, \& Maddux, 2007).

Do not become too discouraged if your article is rejected by the first editor. This is a part of the learning process. Consider the editor's comments and revise the manuscript, have some colleagues review the manuscript again, and submit it to another journal for consideration. It takes perseverance, determination, and time to become a successful author. Finally, the following tips could be helpful:

- Budget sufficient time for first draft, second, and third draft.
- Get feedback from colleagues and professors.

- Ask for criticism, not praise.

- Find out the genre of the intended journal as well as the acceptance rate.

- Aim for journals in your field for which the manuscript is appropriate. You will get the best feedback from more prestigious journals.

- Check the journal guidelines before sending your manuscript.

- Volunteer to be a reviewer for a journal or a professional conference. You will learn about the review process and gain experience on the common factors that contribute to publishable and nonpublishable articles.

\section{References}

Liu, L., Yuen, S. C.-Y., \& Maddux, C. (2007). Publishing papers in an academic journal: Guidelines and writing tips [CD-ROM]. In R. Carlsen, K. McFerrin, J. Price, R. Weber, \& D. A. Willis, (Eds.) Proceedings of SITE 2007 Conference (p. 1174-1179). Norfolk, VA: Association for the Advancement of Computing in Education (AACE).

Maddux, C., \& Liu, L. (2005). Publishing research findings: Some suggestions for junior faculty. International Journal of Technology in Teaching and Learning, 1(2), 55-62.

Klinger, J. K., Scanlon, D., \& Pressley, M. (2005). How to publish in scholarly journals. Educational Researcher, 34(8) 14-20.

Socolofsky, S. A. (2004). How to write a research journal article in engineering and science. Retrieved May 14, 2008, from http://www.ifh.uni-karlsruhe.de/lehre/ dokkurs/gutes-schreiben/paper_how-to.pdf 


\section{Contact the Authors}

\section{Steve Chi-Yin Yuen, Ph.D.}

The University of Southern Mississippi

Email: Steve.Yuen@usm.edu

Patrivan K. Yuen, M.A., M.L.I.S., M.Ed.

William Carey University

Email: pyuen@wmcarey.edu

Xiaojing Duan, M.S.

University of Notre Dame

Email: xiaojing.duan@gmail.com 